\title{
Co-Existence of Chronic Lymphocytic Leukaemia and Malignancy of Uterine Cervix
}

\author{
Uttara Vijay Shelke1, Shourya Acharya ${ }^{2}$, Deepti Sandeep Shrivastava ${ }^{3}$
}

\begin{abstract}
${ }^{1}$ Department of Obstetrics and Gynaecology, Acharya Vinoba Bhave Rural Hospital, DMIMS, Sawangi, Wardha, Maharashtra, India. ${ }^{2}$ Department of Medicine, Acharya Vinoba Bhave Rural Hospital, DMIMS, Sawangi, Wardha, Maharashtra, India. ${ }^{3}$ Department of Obstetrics and Gynaecology, Acharya Vinoba Bhave Rural Hospital, DMIMS, Sawangi, Wardha, Maharashtra, India.
\end{abstract}

\section{INTRODUCTION}

Chronic Lymphocytic Leukaemia (CLL) is the most common variety of leukaemia. In this disease B-lymphocytes which would normally respond to antigens by transformation and forming antibodies, fail to do so. Patients with chronic lymphocytic leukaemia have up to a threefold risk of site specific secondary cancers. However, the co-existence of chronic lymphocytic leukaemia with gynaecological cancers is a rare phenomenon. Expert clinical and pathological review is warranted for proper diagnosis and management. Here we report a case of 57 year old patient with co-existent CLL and squamous cell carcinoma of the uterine cervix.

Chronic Lymphocytic Leukaemia (CLL) is the most common leukaemia affecting the western world. It occurs mostly in the elderly.[1] It is less frequent in the Asian population. CLL is characterized by clonal proliferation and accumulation of mature, typically, CD5 positive B-cells within the bone marrow, spleen, blood and lymph nodes.[2]

An increased risk of another (second) cancer in patients with CLL was reported in few studies. ${ }^{[3]}$ These second cancers in CLL may be due to patient related risk factors, chemotherapy specific factors such as immunosuppression. Certain studies have given a report that second cancers may occur with similar frequency whether they developed concurrently or after the diagnosis of CLL. Immunodeficiency in CLL may predispose to development of a second cancer. [4],[5]

\section{PRESENTATION OF CASE}

A 57-year-old patient presented to medicine department of this hospital with complaints of generalized weakness, weight loss and fatigue. On clinical examination she had anaemia, splenomegaly $13 \mathrm{cms}$, firm non tender, below left costal margin. There was no lymphadenopathy. Hb- 7.2 grams. Peripheral smear was suggestive of CLL. Marrow aspirate showed $80 \%$ small atypical lymphocyte. She was diagnosed as CLL stage III (Rai staging). Patient received chemotherapy with Cyclophosphamide, Vincristine, Prednisolone and Chlorambucil.

Later, in the same month, she presented to gynaecology OPD with complaints of leucorrhoea and bleeding per vaginum since 8 days. On general examination vitals were stable. On per speculum examination bleeding through os was present. On per vaginal examination uterus was atrophied, cervix was pinpoint, fornices were free. Patient underwent total abdominal hysterectomy with bilateral salpingooophorectomy with omentectomy without any complications and the specimen was sent for histopathological examination. Patient is on follow up.

\author{
Corresponding Author: \\ Dr. Sourya Acharya, \\ Department of Medicine, \\ Acharya Vinoba Bhave Rural Hospital, \\ DMIMS, Sawangi, Wardha, Maharashtra, \\ India. \\ E-mail: souryaacharya74@gmail.com
}

DOI: $10.14260 /$ jemds $/ 2020 / 332$

Financial or Other Competing Interests: None.

How to Cite This Article:

Shelke UV, Acharya S, Shrivastava DS. Coexistence of chronic lymphocytic leukaemia and malignancy of uterine cervix. J. Evolution Med. Dent. Sci. 2020;9(18):15221524, DOI: $10.14260 /$ jemds/2020/332

Submission 06-01-2020, Peer Review 17-04-2020, Acceptance 23-04-2020, Published 04-05-2020.

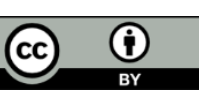




\section{PATHOLOGICAL DISCUSSION}

Section from endometrium shows senile cystic atrophy. Section from polypoidal mass in endometrium cavity shows endometrial polyp. Section from cervix shows squamous cell carcinoma (non-keratinizing). Stromal invasion more than 3 $\mathrm{mm}$ and not more than $5 \mathrm{~mm}$ with a horizontal spread of $7 \mathrm{~mm}$ or less suggestive of stage ia2. Bilateral ovaries were unremarkable on histopathology. Section from the omentum was negative for infiltration by malignant cells.
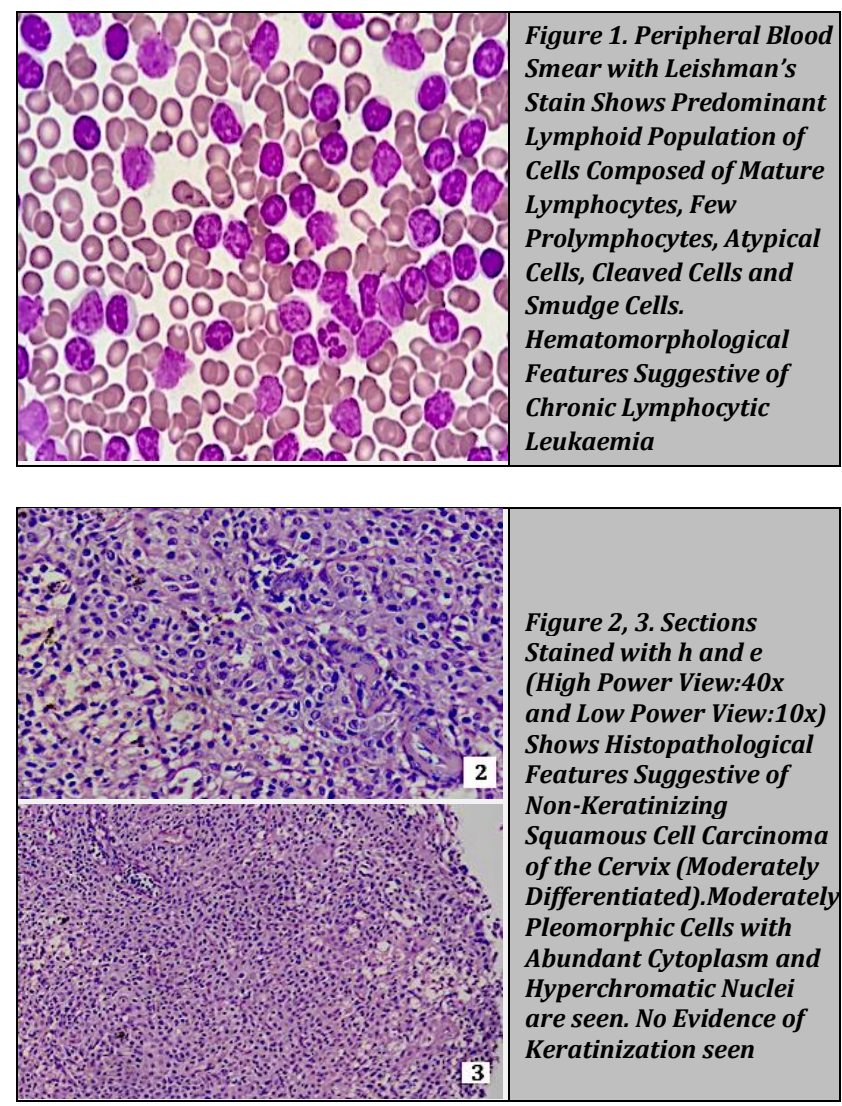

\section{DISCUSSION}

A study of literature has showed that various malignancies have known to occur concurrently or after the diagnosis of CLL.[6-11] In a retrospective study, it was found that in patients with CLL, the risk of all types of cancers was three-fold; the risk of skin cancer was about eight-fold, and the risk of all cancers excluding skin cancer was two-fold higher than that for same age and sex control population.[12]

Formation of second cancers after chemotherapy in leukaemias/lymphomas has been reported in few studies. We diagnosed these two malignancies; that is CLL with cervical cancer concurrently during our management.

In another study, the risk of a second neoplasm in patients with CLL was increased 2.2 times as compared to the risk for a healthy population.[6] Schollkopf et al. evaluated the records of 12,373 patients diagnosed with CLL/SLL between 1943 and 2003. Cancers were found in 1,105 cases, 20 of them originated from the female genital tract ( 4 from the uterine cervix, 7 from the uterus, 8 from the ovary, fallopian tube, and broad ligament, and a tumor with no specific localization).[7]
The risk for the development of gynaecological cancers in women with CLL was lower (standardized incidence ratio $=$ 0.64).[7] Dong and Hemminki studied the site-specific risk of second primary malignancies in 53,159 hematolymphoproliferative disorder cases diagnosed between 1958 and 1996. They used the Swedish family-cancer database. Gynaecological neoplasms were diagnosed in only 40 women with hematolymphoproliferative disorder during this period, of which 12 originated from the endometrium.[10] The management of CLL depends on the staging, patient's age, general condition of the patient, co-morbidities and prognostic factors. Most patients in early stage are managed with wait and watch approach. Patients with advanced disease have two possibilities of treatment options; chemotherapy and or stem cell transplantation. The management of the secondary cancer is not much different from the treatment of a primary cancer/de novo developing cancer. However the risks related to treatment of primary type of cancer are to be kept in mind.

\section{CONCLUSIONS}

The occurrence of a gynaecologic cancer along with CLL is a relatively rare phenomenon. Increased awareness of this association is required. Development of surveillance strategies may be needed in the future for an increasing population of surviving patients who are at risk for second neoplasms.

\section{REFERENCES}

[1] Dogu MH, Sari I, Hacioglu S, et al. Two rare diagnoses during chronic lymphocytic leukaemia follow-up: Kaposi's sarcoma and Merkel cell carcinoma. Scott Med J 2016;61(1):60-3.

[2] Hallek M, Cheson BD, Catovsky D, et al. Guidelines for the diagnosis and treatment of chronic lymphocytic leukaemia: a report from the International Workshop on Chronic Lymphocytic Leukaemia updating the National Cancer Institute-Working Group 1996 guidelines. Blood 2008;111(12):5446-56.

[3] Soussi G, Daboussi S, Mhamdi S, et al. Second lung malignancy and Richter syndrome in chronic lymphocytic leukemia case report and literature review. Multidiscip Respir Med 2017;12(1):24.

[4] Santoro A, Rilke F, Franchi F, et al. Primary malignant neoplasms associated with chronic lymphocytic leukemia. Tumori 1980;66(4):431-7.

[5] Greene MH, Hoover RN, Fraumeni Jr JF. Subsequent cancer in patients with chronic lymphocytic leukemia--a possible immunologic mechanism. J Natl Cancer Inst 1978;61(2):337-40.

[6] Tsimberidou AM, Wen S, McLaughlin P, et al. Other malignancies in chronic lymphocytic leukaemia/small lymphocytic lymphoma. J Clin Oncol 2009;27(6):904-10.

[7] Schöllkopf C, Rosendahl D, Rostgaard K, et al. Risk of second cancer after chronic lymphocytic leukaemia. Int J Cancer 2007;121(1):151-6.

[8] Wiernik PH. Second neoplasms in patients with chronic lymphocytic leukaemia. Curr Treat Options Oncol 2004;5(3):215-23. 
[9] Molica S. Second neoplasms in chronic lymphocytic leukaemia incidence and pathogenesis with emphasis on the role of different therapies. Leuk Lymphoma 2005;46(1):49-54.

[10] Dong C, Hemminki K. Second primary neoplasms among 53,159 haematolymphoproliferative malignancy patients in Sweden, 1958-1996: a search for common mechanisms. Br J Cancer 2001;85(7):997-1005.
[11] Mudie NY, Swerdlow AJ, Higgins CD, et al. Risk of second malignancy after non-Hodgkin's lymphoma a British Cohort Study. J Clin Oncol 2006;24(10):1568-74.

[12] Manusow D, Weinerman BH. Subsequent neoplasia in chronic lymphocytic leukemia. JAMA 1975;232(3):267-9. 